\title{
O MÉTODO QUALITATIVO NOS ESTUDOS SOCIAIS APLICADOS: DIMENSÕES ÉTICAS E POLÍTICAS
}

\author{
THE QUALITATIVE METHOD IN APPLIED SOCIAL STUDIES: \\ ETHICAL AND POLITICAL DIMENSIONS
}

\author{
Sonia Regina Vargas Mansano \\ Universidade Estadual de Londrina - UEL \\ smansano@sercomtel.com.br
}

Submissão: $26 / 07 / 2013$

Aprovação: 10/02/2014

\begin{abstract}
RESUMO
O presente estudo teve por objetivo problematizar algumas dimensões éticas e políticas que se fazem presentes na formação de pesquisadores na área de estudos sociais aplicados. Para isso, o texto foi dividido em três momentos: primeiramente, buscou-se explorar alguns pressupostos metodológicos das pesquisas qualitativas, com vistas a destacar elementos relevantes para uma abordagem contextualizada e crítica que caracteriza esse tipo de investigação. Em seguida, buscou-se compreender a pesquisa qualitativa em um campo problemático. No terceiro momento, foram discutidos alguns aspectos éticos e políticos que se fazem presentes em cada momento da preparação e execução da pesquisa, desde a elaboração do referencial teórico até a coleta, organização, análise e devolução dos dados. Nas considerações finais, o artigo buscou fazer uma análise sobre os desafios colocados para a formação dos pesquisadores que optam pela elaboração de pesquisas qualitativas na área de estudos sociais aplicados, destacando a importância da transformação de seus agentes no processo investigativo.
\end{abstract}

Palavras-chave: Método qualitativo. Ética. Política. Formação de pesquisadores.

\begin{abstract}
The present study aims to problematize some ethical and political dimensions that are present in the formation of researchers in the area of social studies. To do this, the text was divided into three phases: first, he has been trying to explore some qualitative research methodological assumptions, in order to highlight elements relevant to a critical and contextualized approach that characterizes this type of research. Then he has been trying to understand the qualitative research in a field. In the third time, were discussed some ethical and political aspects that are present in every moment of preparation and execution of the research, from the theoretical to the collection, organization, analysis and return the data. Finally, the article sought to make an analysis on the challenges posed for the training of researchers who opt for elaboration of qualitative research in the area of applied social studies, highlighting the importance of the transformation of its agents in the investigative process.
\end{abstract}

Keywords: Qualitative method. Ethics. Politics. Training of researchers. 


\section{INTRODUÇÃO}

As pesquisas realizadas na área de estudos sociais aplicados colocam a seus estudiosos o desafio de compreender a existência humana em sua dimensão complexa e multifacetada. Para isso, os métodos qualitativos vêm sendo cada vez mais utilizados como estratégia de investigação, no intuito de acompanhar as transformações que acontecem na história, nas organizações e nas relações sociais. No lugar da busca por generalizações, padronizações, quantificações e índices, tais pesquisas ocupam-se de problematizar os acontecimentos em sua emergência histórica, atentando para sua singularidade e para o delineamento de novas realidades sociais.

É possível considerar, então, que os problemas analisados na pesquisa qualitativa, ao invés de serem rapidamente "resolvidos", são objetos de uma apreciação lenta e minuciosa que tende a multiplicar, a transmutar e a desdobrar questões, agregando à investigação uma dimensão problematizadora. Nessa perspectiva, as questões poderão ser mais exploradas à medida que são apreciadas por diferentes agentes, localizados em distintos contextos sociais, os quais poderão participar da investigação multiplicando os ângulos de análise. Com isso, a diversidade de contribuições teóricas e empíricas faz da investigação qualitativa um ensaio complexo de respostas que são sempre parciais e, especialmente, um exercício de elaboração de novas perguntas que colocam em movimento a produção científica.

Seguindo essa maneira de pesquisar, analisam-se algumas questões neste estudo: Quais elementos de investigação e análise dão consistência às pesquisas qualitativas? Quais são seus objetivos? Como essa estratégia de investigação procede? Quais habilidades e sensibilidades são demandadas do pesquisador que se lança nesse tipo de investigação? Quais dimensões éticas e políticas são atualizadas nessa metodologia de pesquisa? Foi precisamente esse conjunto de questões que cooperou para dar contornos a este estudo que teve por objetivo problematizar algumas dimensões éticas e políticas presentes na formação de pesquisadores na área de estudos sociais aplicados. Parte-se da perspectiva de que tal formação é desafiadora uma vez que põe em evidência a tarefa de produzir conhecimentos sobre uma realidade social que é caracteristicamente mutante. Isso demanda um método capaz de manter-se, também ele, em movimento. 
Assim, a opção por utilizar um método qualitativo nos estudos sociais aplicados requer que se demore um pouco nas palavras que lhe dão nome. A palavra "método" refere-se ao "procedimento, técnica ou meio de se fazer alguma coisa de acordo com um plano" (HOUAISS, 2001). Portanto, é possível definir um método para alcançar objetivos nas mais diferentes dimensões da existência. Especificamente nas pesquisas acadêmicas, definir um método consiste em organizar, planejar e seguir um trajeto de investigação (teórica e empírica) por meio do qual se buscará produzir algum tipo de conhecimento sobre um aspecto específico da vida em sociedade.

Obviamente, essa organização sofrerá diversas mudanças no decorrer da pesquisa. É nesse sentido que ganha relevância o vocábulo "qualitativo". Ele indica que a pesquisa envolverá também o contato com diferentes agentes sociais que atribuem qualidades e sentidos distintos àquilo que está sendo investigado. Por meio dessa atribuição singular de qualidades, vão-se analisando as maneiras como um fato ou acontecimento ganha consistência para aquele sujeito, grupo e/ou instituição, situados em um contexto e em um momento histórico específicos, podendo ganhar outros contornos com o passar do tempo. É precisamente essa busca pela atribuição de sentidos e qualidades à experiência que torna esse método problematizante.

Em meio a esse debate, o estudo foi dividido em três momentos. Primeiramente, serão destacadas e analisadas algumas características da pesquisa qualitativa, bem como as inquietações que elas tendem a provocar no pesquisador. Em seguida, serão discutidos os processos de aprendizagem colocados em curso no decorrer da pesquisa, uma vez que seu diferencial consiste em acolher e sustentar um campo problemático. Analisam-se, então, alguns desafios éticos e políticos enfrentados pelos pesquisadores que optam por esse tipo de metodologia. Por fim, já nas considerações finais, busca-se indagar sobre a formação do pesquisador que escolhe esse método de pesquisa, mostrando o quanto a sua execução requer sensibilidade e abertura para $o$ questionamento, e esse último não necessariamente se esgota com o término da investigação.

Antes de se iniciar, porém, cabe destacar que o campo qualitativo em investigação social exige uma abertura metodológica capaz de acompanhar sutilezas, desvios e mudanças dos problemas investigados, fato que inviabiliza a escolha de um método fechado e rígido. No decorrer deste estudo, faz-se um diálogo com 
pesquisadores contemporâneos que se dedicam a analisar as dificuldades e os desafios enfrentados em uma pesquisa social cuja elaboração envolve caminhos díspares e multifacetados.

\section{DELINEANDO ALGUMAS CARACTERÍSTICAS DA PESQUISA QUALITATIVA}

A opção por adotar o método qualitativo em pesquisas realizadas na área de estudos sociais aplicados é algo relativamente recente e conta com uma série de dificuldades em sua elaboração, planejamento e execução (GODOI; BALSINI, 2010). Essa escolha coloca os pesquisadores em um campo problemático que exigirá uma série de cuidados, os quais vão desde a definição do tema a ser pesquisado, passam pela elaboração do referencial teórico que norteará a elaboração de conhecimentos, contemplam a maneira de coletar os dados e chegam às análises, compostas pela articulação entre as partes teórica e empírica da pesquisa.

As ciências humanas já possuem ampla tradição nesse tipo de investigação e, em razão disso, seus pressupostos metodológicos são mais conhecidos e assimilados. É inegável que, para uma área que tradicionalmente tem adotado os estudos quantitativos, a aproximação da pesquisa qualitativa gere alguns estranhamentos e, porque não dizer, certos incômodos. O que interessa, na primeira parte deste estudo, é acolher e dar visibilidade a tais incômodos, buscando compreender parte dos elementos que participam da composição desse método. Assim, selecionaram-se alguns pontos que caracterizam a pesquisa qualitativa e serão percorridos de maneira um pouco mais lenta, atentando para suas peculiaridades.

Primeiramente, faz-se necessário compreender quais as concepções de humano que norteiam as pesquisas qualitativas. Afinal, como é possível compreender o sujeito que participa da pesquisa e sua vinculação com o problema investigado? Traz-se, então, para esse debate, a noção de subjetividade sob a perspectiva teórica da Psicologia Social. Para essa área de conhecimento, o humano não nasce dotado de uma essência que simplesmente seria confirmada no decorrer de sua existência (LANE; CODO, 1984). A partir de seu nascimento, inicia-se um processo de produção de si que terá nos encontros sociais suas condições de efetivação. Trata-se de construir a própria 
existência, como sujeito social, no encontro com aquilo que o rodeia: pessoas, objetos, acontecimentos, natureza, conhecimento, arte, enfim, com o mundo em sua multiplicidade. Nesse referencial teórico, portanto, a produção do sujeito mantém-se em aberto e se estende por toda a sua existência.

Precisamente esse estado de inacabamento impede de falar sobre uma essência humana. Foucault mostra em seus estudos uma preocupação recorrente em analisar "o conjunto dos processos pelos quais o sujeito existe com seus diferentes problemas e obstáculos, e através de formas que estão longe de estarem concluídas" (FOUCAULT, 2004, p. 262). No lugar de considerar o sujeito centrado em uma identidade fixa, tem-se, na Psicologia Social, o desafio de problematizar os "processos de subjetivação" (FOUCAULT, 2004, p. 262), ou seja, estudar como são produzidos os modos de viver e de se relacionar que são colocados em curso em um dado momento histórico. Sobre isso, conclui Foucault: "Eu chamaria de subjetivação o processo pelo qual se obtém a constituição de um sujeito, mais precisamente de uma subjetividade, que evidentemente não passa de uma das possibilidades dadas de organização de uma consciência de si" (FOUCAULT, 2004, p. 262).

As pesquisas qualitativas ganham consistência quando se propõem a percorrer a heterogeneidade dessa produção, que envolve práticas, valores, sensações, enunciados e modos de vida. Esse conjunto expressa as diferentes maneiras como o sujeito se conecta ao mundo e as variações subjetivas que seus encontros provocam. Pode-se dizer, então, que a qualidade dessas conexões será o objeto de investigação da metodologia qualitativa.

Com base nessa concepção de humano, considera-se que esse tipo de pesquisa é desenvolvido em um processo de troca e coprodução que conta com diferentes agentes, dentre os quais se destacam dois: os pesquisadores e os sujeitos participantes. Estes, no decorrer do processo investigativo, são amplamente afetados pelo problema investigado e por seus desdobramentos. Com isso, os agentes alteram suas impressões e maneiras de compreender as questões que foram tomadas em apreciação. Nesse sentido, Balasch e Montenegro (2003, p. 45) consideram que "los efectos metodológicos de la conexión parcial con otras posiciones modificaran la posición inicial de las investigadoras, a la vez que localizan y sitúan el conocimiento producido en un entramado relacional”. Tal rede de relações indica que a posição inicial dos agentes das pesquisas "es susceptible 
de ser alterada" (BALASCH; MONTENEGRO, 2003, p. 45)) durante a investigação e é precisamente esse um dos elementos que contribui para delinear as pesquisas qualitativas: pesquisadores e sujeitos participantes transformam-se no decorrer do processo.

Chega-se, então, a outra característica desse tipo de investigação: ela acompanha o movimento e a singularidade dos acontecimentos sociais com um método que está, também ele, em movimento. Daí a importância de manter-se atento à composição provisória dos problemas estudados e aos múltiplos efeitos subjetivos que são por eles produzidos. Nota-se que as pesquisas movem-se num campo em que seus agentes se veem em situações de incertezas, na multiplicação das questões e na invenção de respostas provisórias. Foucault pode novamente contribuir para a compreensão da pesquisa qualitativa ao considerar que a "transformação de um conjunto de complicações e dificuldades em problemas para os quais as diversas soluções tentarão trazer uma resposta é o que constitui o ponto de problematização e o trabalho específico do pensamento" (FOUCAULT, 2004, p. 233). As pesquisas qualitativas acolhem esse trabalho de pensar o vivido em sua dimensão problemática e ampla.

É nesse sentido que os problemas analisados podem ganhar contornos incômodos e provocar estranhamento e, por isso mesmo, pôr os investigadores em contato mais direto com os limites do desconhecido. As pesquisas qualitativas mantêmse precisamente na vizinhança desse desconhecimento, já que não se sabe, de antemão, o que advirá dos dados e que tipo de análise poderá ser elaborado sobre eles. Daí seu caráter radicalmente aberto que tende, até mesmo, a dispensar a formulação de hipóteses. Uma hipótese admite duas possibilidades: ser refutada ou confirmada. Já a pesquisa qualitativa tem outro objetivo: compreender como uma dada situação é vivida e quais sentidos lhe são atribuídos pelo sujeito. E, além disso, ela busca apreender as transformações que acontecem nesse plano, atentando para os novos sentidos que vão sendo atribuídos durante a elaboração do vivido pelo participante. Constata-se, portanto, que a definição de uma hipótese tende a restringir essa maneira de investigar, por comportar, de saída, apenas duas possibilidades (refutar ou confirmar) para conclusão do estudo.

Destaca-se, assim, outra característica desse tipo de pesquisa: ela mantém-se distante das noções de regularidade e generalização, categorias por demais cristalizadas 
para acompanhar as sutilezas presentes na produção dos modos de viver e que não são facilmente apreendidas pelos índices e quantificações. O que interessa nessa investigação é manter o pesquisador o mais próximo possível da experiência vivida pelo sujeito participante e das qualidades e sentidos que lhe são atribuídos, assim como de seus desvios e imprevistos. Obviamente, a busca por generalizações e regularidades fazse presente nos estudos sociais aplicados, mas vale dizer que, quando se busca alcançar esse objetivo, o método qualitativo não é a melhor opção.

Dessa maneira, a pesquisa qualitativa busca compreender como se dá a composição provisória das experiências e também qual sua funcionalidade na ocasião em que emergiram. Com isso, é importante que a concepção de um sujeito cristalizado em um todo coerente e estável, historicamente caracterizado como sujeito moderno, seja superada, dando espaço à investigação sobre as múltiplas possibilidades de fazer-se sujeito nas relações sociais. Pode-se, então, dar um passo adiante e considerar que "las enunciaciones que se producen en el habla no actualizan un sujeto, una voz, sino una red de relaciones que sitúan el relato. Por lo tanto, es posible otorgarle procedência, un lugar desde el cual es producido este relato, pero no quién lo produce" (BALASCH; MONTENEGRO, 2003, p. 46). Isso porque quem vive a experiência e lhe atribui sentidos não é um sujeito isolado, mas sim alguém conectado a uma rede social ampla e multifacetada.

Quando a pesquisa qualitativa é associada a uma investigação em profundidade, o que se pretende é dar visibilidade precisamente a esses movimentos de produção do sujeito na experiência. Assim, está-se diante de um processo de investigação que busca conhecer a produção diferenciada e mutante do participante nas redes relacionais (uma heteroprodução), visto que o objetivo dessa metodologia de pesquisa consiste em conhecer as múltiplas dimensões colocadas em curso por esse movimento, as quais, por sua vez, podem ser transformadas com o passar do tempo, incluindo-se aí o tempo dedicado à pesquisa. Daí a necessidade de escolher um método aberto para possíveis desvios, que se mantenha em movimento e seja capaz de acompanhar as minúcias dos depoimentos (dados) cedidos pelos sujeitos participantes que, como se está afirmando desde o início deste estudo, também estão em movimento e, em função disso, poderão fornecer um material por vezes confuso, díspar e contraditório sobre as maneiras como experimentam o problema que está sendo investigado. 
As características que se acaba de descrever obviamente não esgotam a pesquisa qualitativa, mas servem para mostrar o quanto ela lança os pesquisadores e participantes em um campo complexo de problematizações no qual, como se vê a seguir, são elaboradas e analisadas questões e respostas parciais.

\section{O CAMPO PROBLEMÁTICO E AS PESQUISAS QUALITATIVAS}

Desde já, é possível notar que as pesquisas qualitativas são realizadas por contato, acolhimento e elaboração da experiência. Nelas, pesquisadores e participantes encontram-se diante da difícil tarefa de elaborar questões: Afinal, como esse fato acontece? Em quais circunstâncias? Onde? Por quê? De que modo ele emerge no social? Quem dele participa? Quais efeitos produzem? Tais questões buscam circunscrever parcialmente as condições que possibilitam a experiência ou o acontecimento estudado, sua dimensão histórica e os efeitos que produzem naquele sujeito ou grupo específico. Com essas questões, visa-se acompanhar a incessante produção de sentidos que inclui impressões, valores, desejos, implicações subjetivas e sensações que atravessam tanto o pesquisador quanto o sujeito participante.

A análise desses dados heterogêneos se faz à medida que as questões elaboradas no contato com o campo social cooperam para elaborar diferentes saberes. Como já dito, as qualidades atribuídas ao vivido não se prestam à estagnação, porquanto as respostas (salientadas, são sempre provisórias e em perspectiva) tendem a ser superadas e transformadas no decorrer das investigações. Dessa maneira, nenhum conhecimento elaborado é capaz de interromper o fluxo da produção de questões e respostas.

Os campos problemáticos percorridos nas pesquisas qualitativas são móveis e transitórios, tendo seus resultados descritos e analisados no limite do que é possível conhecer. E esse limite é evidenciado quando o sujeito participante, bem como o pesquisador, transforma suas maneiras de relatar e atribuir sentidos ao vivido. $\mathrm{O}$ foco dessa investigação consiste em acompanhar precisamente esse movimento de ruptura em que os sujeitos transitam por posições e opiniões as mais distintas.

A escolha por esse tipo de metodologia, portanto, lança o pesquisador no complexo jogo que comporta simultaneamente problemas, dúvidas, soluções parciais, bem como o abandono de convicções e análises descontextualizadas. É nesse sentido 
que a investigação qualitativa aciona a possibilidade de acompanhar e criar novas análises para o problema que está em pauta. E, para fazer isso, é precioso que o pesquisador esteja atento à dimensão singular e mutante das experiências que lhe são relatadas. Nesse campo, são os problemas que o forçam a pensar, a questionar as convicções e verdades, a elaborar novas questões, a desconstruir ou colocar em xeque as respostas muito naturalizadas e a percorrer ângulos de análise até então inexplorados.

Pode-se dizer que uma pesquisa qualitativa consolida-se como um exercício de transformação de seus partícipes (pesquisadores e participantes) quando põe em curso o questionamento sobre aquilo que já é conhecido e aceito como "natural". Godoi, Bandeira-de-Melo e Silva (2010, p. 4) assinalam que "a abertura à experiência modifica o próprio pesquisador em favor do discurso ou da situação, ou seja, o pesquisador é invadido e construído pela experiência".

Há ainda outro elemento a ser considerado na caracterização do campo problemático da pesquisa qualitativa que compreende o desaparecimento dos limites claros entre o pesquisador e o participante. Assim,

si conceptual y formalmente investigadora y participante crean narrativas alternativas de la realidad, dificilmente puede justificarse que una (la de la investigadora) sea "teórica" mientras que la outra (la de la participante) sea "empírica". Ambas son versiones teóricoempíricas: teóricas porque nos ofrecen un 'conocimiento' del mundo; empíricas porque son productos de una serie de procedimientos establecidos a priori (PUJOL; MONTENEGRO; BALASCH, 2003, p. $67)$.

Nota-se que, no lugar da nítida separação entre pesquisador de um lado e participante de outro, ganha relevância o contato direto entre os agentes da pesquisa, tomando-se em consideração os diferentes ângulos que podem ser por eles explorados. E isso abre espaço para se analisar outro incômodo bastante comum nas pesquisas qualitativas: a questão da neutralidade. Levando-se em conta o fato de que a investigação qualitativa busca dar visibilidade a múltiplos valores e perspectivas de análise, os incômodos e as dúvidas gerados tanto nos pesquisadores quanto nos participantes consolidam-se como valiosa fonte de dados que funciona como uma espécie de "motor" para as questões. Sendo assim, no lugar da neutralidade, ganha importância a implicação dos envolvidos com o problema investigado. Tal implicação evidencia que há uma sensibilidade acionada para a pesquisa. E essa sensibilidade 
permite continuar questionando, afinal: Quais estratégias podem ser utilizadas para promover maior aproximação da problemática investigada? Quais elementos subjetivos participam da produção de uma dada maneira de viver? Quais são as práticas relacionais envolvidas? Que tipo de saber é extraído daí e como ele é apropriado pelos agentes no cotidiano das relações sociais?

Reconhecer nessas questões a diversidade complexa das respostas parciais que perpassam uma pesquisa qualitativa, ora atentando para as reversões experimentadas entre os agentes, ora rompendo com as verdades mais cristalizadas, ora, ainda, questionando os modos de viver que são assumidos em um dado momento histórico, é a maior contribuição que pode advir desse tipo de investigação. Foucault (2004, p. 232) diz que "várias respostas podem ser dadas para um mesmo conjunto de dificuldades. $\mathrm{Na}$ maior parte do tempo, diversas respostas são efetivamente propostas. Ora, o que é preciso compreender é aquilo que as torna simultaneamente possíveis" e que, por isso mesmo, lança os pesquisadores e participantes em um campo de investigação mutante.

Sem a pretensão de esgotar este debate, destaca-se um último elemento que compõe este campo: além dos movimentos de investigação, também são precipitadas, nesse tipo de estratégia de pesquisa, diversas experiências de criação. Valendo-se de respostas parciais e circunstanciais, essa metodologia oferece aos pesquisadores e participantes a oportunidade de exporem-se a uma complexa rede de coprodução dos saberes, dos modos de vida, dos acontecimentos, da organização social e da história. É nessa perspectiva de criação que as dimensões éticas e políticas da pesquisa são, em seguida, abordadas.

\section{DIMENSÕES ÉTICAS E POLÍTICAS DA PESQUISA QUALITATIVA}

São diversos os desafios éticos e políticos presentes na formação de um pesquisador que se dedica à metodologia qualitativa. No entendimento do autor deste artigo, tal formação se estende pelo tempo em que esse pesquisador estiver vinculado a essa atividade, em razão de as dificuldades enfrentadas e assumidas serem recolocadas a cada nova pesquisa, fazendo desta um campo complexo marcado pelo acaso, pelas surpresas e incertezas. Se fosse diferente, ou seja, se já se soubessem, de antemão, os resultados aos quais uma pesquisa qualitativa chegaria, não faria sentido dar-lhe 
continuidade. Lembra Foucault (2004, p. 288): “Quando se sabe de antemão onde se quer chegar, falta uma dimensão da experiência, a que consiste precisamente em escrever um livro correndo o risco de não chegar ao fim”. É essa dimensão de desconhecimento e imprevisibilidade que move os problemas na metodologia qualitativa. Seu diferencial está no fato de que ela afirma o caráter "em aberto" da investigação, bem como seus riscos, acentuando o quanto as dimensões éticas e políticas precisam ser amplamente consideradas e debatidas nesta área.

Inicia-se, então, pela análise da dimensão ética. Conceito amplamente estudado pela filosofia e reapropriado por diferentes áreas de conhecimento, a noção de ética também se faz presente no universo das pesquisas qualitativas, incluídas aí as que são realizadas na área de estudos sociais aplicados. Dentre as diversas maneiras de se abordar esse conceito, recorre-se aqui a uma delas: Deleuze (2002, p. 29), ao estudar a noção de ética em Espinosa, mostra que esta pode ser compreendida como "uma tipologia dos modos de existência". Sob essa perspectiva, um exercício ético implicaria compreender o humano na singularidade que o atravessa, acompanhando e analisando os modos de vida que são inventados e colocados em circulação por ele em um dado contexto social e histórico. Dessa maneira, pensar eticamente a vida suscita questões como: Afinal, o que se está inventando como modo de viver? Quais os efeitos dessa invenção? Como se conduzir diante dela?

Tomando essas questões para análise, Deleuze (2002, p. 29) acrescenta que a "ética desarticula o sistema de julgamento", evitando avaliações de tipo moral que tendem a separar e julgar aquilo que é considerado como sendo do "bem", por um lado, ou do "mal", por outro. Nessa perspectiva ética, "a oposição dos valores (...) é substituída pela diferença qualitativa dos modos de existência” (DELEUZE, 2002, p. 31). Portanto, nesse referencial teórico, a ética é associada à qualidade singular da experiência que, por sua vez, é o objeto de investigação das pesquisas qualitativas.

Mas, como essa questão é tratada no meio acadêmico? Os cuidados éticos a serem considerados em uma pesquisa estão sendo cada vez mais debatidos nas instituições de ensino superior, exigindo de seus agentes a abertura para o diálogo e confronto de posições, visto não serem as disposições éticas perenes ou homogêneas. Abordar a ética como produção histórica implica considerá-la acima da prescrição e do conjunto de regras. Além disso, seu exercício é pleno de conflitos, os quais explicitam 
as diferenças de valores, de posturas e de procedimentos que se atualizam nos variados modos de fazer pesquisa acadêmica. Pode-se dizer que esses enfrentamentos, quando encontram espaço para serem expressos, analisados e debatidos, dão indícios de que um exercício ético está em curso.

De qualquer maneira, destacam-se aqui dois aspectos que envolvem a noção de ética em pesquisa acadêmica: um documental e outro prático. No que se refere ao primeiro aspecto, o documental, as atividades de pesquisa acadêmica têm sofrido modificações em relação às novas exigências legais colocadas tanto para os pesquisadores quanto para os participantes: são códigos, resoluções federais, comitês de ética, elaboração de documentos e sucessivas avaliações que passaram a compor a tramitação e execução dos projetos de pesquisa - hoje a área de conhecimento que se encontra mais regulamentada é a da saúde, precisamente por envolver estudos diretos com animais e seres humanos. Os cuidados éticos a serem observados nesse tipo de pesquisa são estabelecidos pela Resolução n. 466/2012 do Conselho Nacional de Saúde (BRASIL, 2012), que define, como condição indispensável, o chamado "assentimento livre e esclarecido". Tal documento visa tratar os participantes "em sua dignidade, respeitá-los em sua autonomia e defendê-los em sua vulnerabilidade" (BRASIL, 2012), informando-lhes sobre os detalhes a serem explorados pela pesquisa, a maneira como acontecerá sua participação bem como a possibilidade de desistência em qualquer momento do processo investigativo.

Apesar de não se estar, aqui, envolvido diretamente com a área de saúde, é possível reconhecer nessa resolução um índice das responsabilidades legais que se fazem presentes na coleta e análise dos dados em pesquisa. Entretanto, quando esse debate fica vinculado exclusivamente ao campo legal e substitui uma problematização sobre a singularidade das pesquisas, o resultado é a cristalização prescritiva que, no entendimento do autor deste artigo, compromete a própria prática ética, fazendo incidir sobre ela aquela avaliação moral assinalada anteriormente com Deleuze.

Se, como já dito, parte-se de uma concepção de sujeito como alguém que está em produção, não é possível estagnar a discussão ética, desconsiderando-se ou mesmo minimizando-se a problematização sobre sua dimensão prática, mutante e polêmica. Trata-se de um exercício que implica o envolvimento de seus agentes (pesquisadores e participantes) no debate sobre os problemas que são enfrentados no decorrer das 
pesquisas e seus mais variados desdobramentos. Entretanto, essa mesma concepção de ética que acolhe as múltiplas possibilidades do existir e suas mutações aponta outra dificuldade: até que ponto seu exercício é possível no contexto acadêmico de pesquisa?

É nesse sentido que cabe resgatar o segundo aspecto ético, que se estende para além dos documentos e trâmites instituídos na operacionalização das pesquisas e evidencia algumas dimensões práticas a serem observadas durante cada momento da execução do estudo. A prática ética faz-se presente desde a definição do problema, passando pela construção do referencial teórico, pelo modo como os participantes serão abordados e acolhidos nas pesquisas, pela maneira de analisar dos dados e, por fim, pela devolução dos resultados. Há, nesse trajeto, diferentes decisões éticas a serem tomadas pelos pesquisadores, que darão uma direção singularizada ao estudo.

A definição de um problema de pesquisa consolida-se como um momento delicado. Por vezes, o tema geral já foi definido pelo grupo de pesquisa ao qual o pesquisador pertence ou pretende pertencer. Nesse sentido, o conhecimento prévio da temática investigada pelo grupo (geralmente vinculado aos programas de pósgraduação) torna-se relevante, uma vez que os temas das pesquisas emergem desse coletivo e vão acompanhar o pesquisador por alguns anos de sua vida. Entretanto, como dito anteriormente, a metodologia qualitativa caracteriza-se pela implicação do pesquisador com o tema de investigação. Essa implicação será tanto mais consistente quanto mais o pesquisador vincular-se conceitual e subjetivamente à temática, envolvendo-se com dilemas, confrontos e valorações que ela suscita. Sem essa implicação, fica mais difícil definir e envolver-se com um tema de pesquisa que, nesse caso, corre o risco de manter-se alheio aos interesses do pesquisador em formação. Sobre isso, Alvarez e Passos assinalam:

\footnotetext{
Conhecer não é tão somente representar o objeto ou processar informações acerca do mundo supostamente já constituído, mas pressupõe implicar-se com o mundo, comprometer-se com a sua produção. Nesse sentido, o conhecimento ou, mais especificamente, o trabalho da pesquisa se faz pelo engajamento (ALVAREZ; PASSOS, 2010, p. 131).
}

Vale salientar que esse engajamento não está dado a priori. Ele é construído no envolvimento teórico e subjetivo do pesquisador para com o tema a ser explorado, mas também na relação com o grupo de pesquisa com o qual dialoga. Daí a relevância de conhecer, ainda que minimamente, os trabalhos realizados pelos programas de pós- 
graduação, buscando fazer articulações com os problemas neles investigados. É nessa aproximação que se constrói uma prática ética.

Paralelo ao exercício ético, cabe sublinhar outra dimensão colocada em curso nas pesquisas qualitativas: a política. Esta também implica uma prática que tem início desde os primeiros momentos em que se define um tema de pesquisa, pelo fato de que, desde lá, o pesquisador já começa a dedicar-se à problematização de uma esfera específica da experiência social, colocando-se em um exercício de questionamento, aproximação, sensibilização e apreciação de problemas. A dimensão política pode ser encontrada na maneira como o pesquisador organiza e dirige a investigação, tornando-a singular. Assim, um mesmo tema ganha contornos diferentes quando estudado por pesquisadores diferentes. A variação, neste caso, é atualizada pela posição política tomada por cada um dos pesquisadores que dirige suas investigações para problemas, ângulos, situações e epistemologias distintos. Passos e Barros entendem a política em pesquisa:

como uma posição que tomamos quando, em relação ao mundo e a si mesmo, definimos uma forma de expressão do que se passa, do que acontece. Sendo assim, o conhecimento que exprimimos acerca de nós mesmos e do mundo não é apenas um problema teórico, mas um problema político (PASSOS; BARROS, 2010, p. 151).

A entrada dos participantes dá continuidade a essa dimensão política da pesquisa, visto serem eles que fornecem os dados e, ao fazê-lo, também passam a problematizar as experiências vividas, explorando ângulos de análise que até poderiam ficar inacessíveis sem a intervenção questionadora do pesquisador. Pesquisadores e participantes praticam, assim, um exercício ético e político por meio do qual a experiência investigada e as relações sociais que lhes dão sustentação são amplamente analisadas, exploradas, questionadas e, por que não dizer, reinventadas, num exercício que comporta a organização, direção e cocriação de conhecimento.

Alguns dos autores que compareceram neste estudo (PASSOS; KASTRUP, 2010; ESCÓSSIA; BARROS, 2010; PUJOL; BALASCH; MONTENEGRO, 2003; GODOI; BANDEIRA-DE-MELO; SILVA, 2010) mostraram o quanto as pesquisas qualitativas, ao priorizarem a análise de experiências singulares, podem contribuir para a transformação da realidade social estudada e dos agentes nela envolvidos. Esta é outra dimensão política: desde seus primeiros passos, ela pode alterar a percepção de seus 
agentes sobre o vivido e sobre os problemas analisados, precipitando novas maneiras de agir e se relacionar.

Tal transformação pode efetuar-se desde o momento em que o pesquisador se enfrenta com a necessidade de eleger uma temática de pesquisa até seu fechamento. Aliás, pode-se até mesmo dizer que, em muitos casos, esse exercício político de questionamento e mudança se estende para além da pesquisa, pois as perguntas se transmudam, modificando os incômodos, dando novos contornos aos problemas e suscitando outras questões. A dimensão política presente nesse tipo de pesquisa está precisamente nos efeitos produzidos nos pesquisadores, nos participantes e naqueles que têm acesso aos resultados da investigação. Ainda que envolva efeitos microssociais e de difícil apreensão, esse questionamento pode vir a provocar abalos em algumas convicções que porventura estejam mais estagnadas e até naturalizadas, colocando em movimento a produção de conhecimento.

É notável, então, o quanto as práticas, a ética e a política fazem-se presentes nas pesquisas qualitativas e funcionam como motores para produção de saberes das academias. Diante disso, pode-se considerar que, se a produção de conhecimento científico não caminha nessa direção mutante, tem-se um problema a ser enfrentado: Afinal, para que estão servindo as pesquisas acadêmicas? 


\section{CONSIDERAÇÕES FINAIS}

Após percorrer alguns elementos que dão consistência ao traçado complexo da metodologia qualitativa, a relevância de construir um campo problemático consistente bem como os desafios éticos e políticos a serem enfrentados em uma pesquisa, considera-se que a formação de um pesquisador é algo que demanda não somente preparação teórica, mas, sobretudo, uma sensibilidade para acolher o tema estudado e suas interrogações. Reconhecem-se, assim, os benefícios de promover trocas de experiências entre os pesquisadores, visto que os caminhos investigativos inventados e percorridos por alguns estudiosos podem acionar sensibilidades em outros que, no isolamento, seriam quase inacessíveis. As trocas de experiências, com seus sucessos e fracassos, rupturas e conexões colaboram para fortalecer os pesquisadores que atuam na área dos estudos sociais aplicados, já que, seja qual for a problemática escolhida, estes constatarão a dimensão imprevisível e inacabada que é inerente à condição humana. É precisamente essa mudança de qualidade atribuída às experiências que justifica o estudo aprofundado propiciado pelas pesquisas qualitativas.

Cabe, porém, assinalar que o caráter mutante e imprevisível dessa maneira de produzir conhecimento, presente no método qualitativo, exige um debate constante sobre os desafios éticos que se configuram nesse campo e que não são passíveis de normatização absoluta. Qualquer tentativa nessa direção interromperia o fluxo dos debates e reduziria as dimensões éticas a meras prescrições. Daí a relevância de conceber as pesquisas e a formação do pesquisador em um campo problemático no qual as questões possam ser elaboradas e sustentadas nas dificuldades e riscos que as atravessam. Isso atesta o quanto a produção de conhecimento também coloca em curso movimentos de experimentação, invenção e sensibilidade para com aquilo que está em vias de se afirmar como modo de vida.

A formação de um pesquisador acontece em meio à diversidade de perspectivas epistemológicas, teóricas e metodológicas que poderão ser ensinadas, debatidas e reinventadas desde a sala de aula, passando pelos trabalhos de iniciação científica que são realizados nos cursos de graduação até as pesquisas de pós-graduação. Essa diversidade poderá contribuir para o enriquecimento das metodologias de pesquisa já em curso, bem como para discussão sobre o planejamento e a elaboração de novas 
possibilidades que, como já dito, guardam uma dimensão de incerteza e inacabamento, as quais, longe de se configurarem como limites, são, no entendimento do autor deste artigo, uma das condições para contemplar as singularidades que se expressam nas pesquisas.

Quanto aos limites atribuídos à pesquisa qualitativa, tão amplamente debatidos em estudos sobre metodologia, cabe ressaltar que estes não são pequenos. Como os dados são coletados de maneira aprofundada, buscando dar visibilidade às minúcias do problema que está sendo investigado, isso requer um investimento maior de tempo e dedicação por parte do pesquisador para aprofundar a compreensão do que é vivido pelo participante. Como se vem defendendo no decorrer deste artigo, os sentidos atribuídos pelo sujeito a uma dada experiência investigada são primordiais nesse tipo de pesquisa, uma vez que põem em evidência depoimentos que são histórica e socialmente situados. Assim, um dos maiores desafios está em manter a metodologia em aberto para acolher e analisar os relatos. Nota-se, então, que o diferencial encontra-se precisamente na relação direta entre pesquisador e participante que, juntos, explorando ângulos diferentes de análise, explicitam sua compreensão do problema que está em pauta, valendo-se da vinculação teórica e/ou empírica.

Considera-se aqui que as implicações éticas e políticas acionadas por esse tipo de metodologia, ao contrário de consolidarem-se como limites para efetuação de uma pesquisa, dão consistência à invenção, consolidação e expansão dessa maneira de investigar e de produzir conhecimento. Tal metodologia permite acompanhar e produzir saberes sobre o humano na diversidade em que ele está inserido e na disparidade que as experiências vividas por cada um põe em curso.

Sem contar com a objetividade e a neutralidade dos números e dos tratamentos estatísticos, os desafios éticos e políticos se multiplicam e consolidam-se como exercícios cotidianos a serem amplamente praticados e discutidos tanto nas universidades quanto nos centros de pesquisas. Trata-se, seguramente, de um aprendizado trabalhoso e ininterrupto. Porém, é ele que abre espaço para conceber a formação do pesquisador em uma perspectiva de construção que favorece o questionamento, a crítica e, principalmente, a experimentação de novos caminhos investigativos. 


\section{REFERÊNCIAS}

ALVAREZ, J.; PASSOS, E. Cartografar é habitar um território existencial. In: PASSOS, E.; KASTRUP, V.; ESCÓSSIA, L. Pistas do método da cartografia: pesquisa-intervenção e produção de subjetividade. Porto Alegre: Sulinas, 2010. p. 131149.

BALASCH, M; MONTENEGRO, M. Una proposta metodológica desde la epistemologia de los conocimientos situados: Las producciones narrativas. In:

Encuentros en Psicología Social, v. 1, n. 2, p. 44-48, 2003.

BRASIL. Ministério da Saúde. Resolução 466/2012 do Conselho Nacional de Saúde.

Diário Oficial da União, 12 de dezembro de 2012.

DELEUZE, G. Espinosa: Filosofia prática. São Paulo: Escuta, 2002.

FOUCAULT, M. Ditos e escritos V: ética, sexualidade, política. Rio de Janeiro: Forense Universitária, 2004.

GODOI, K. C.; BALSINI, C. P. V. A pesquisa qualitativa nos estudos organizacionais brasileiros: uma análise bibliométrica. In: GODOI, K. C.; BANDEIRA-DE-MELLO, R.; SILVA, A. B. Pesquisa qualitativa em estudos organizacionais: paradigmas, estratégias e métodos. São Paulo: Saraiva, 2010. p. 106-126.

GODOI, K. C.; BANDEIRA-DE-MELLO, R.; SILVA, A. B. Pesquisa qualitativa em estudos organizacionais: paradigmas, estratégias e métodos. São Paulo: Saraiva, 2010.

HOUAISS, A.; VILLAR, M. S.; FRABCO, F. M. M. Método. Dicionário Houaiss da Língua Portuguesa. Rio de Janeiro: Instituto Antônio Houaiss, 2001. p. 1.910.

LANE, S. T. M.; CODO, W. (Org.). Psicologia Social: o homem em movimento. São Paulo: Brasiliense, 1984.

PASSOS, E.; BARROS, R. B. A Cartografia como método de pesquisa-intervenção. In: PASSOS, E.; KASTRUP, V.; ESCÓSSIA, L. Pistas do método da cartografia: pesquisa-intervenção e produção de subjetividade. Porto Alegre: Sulinas, 2010.

PUJOL, J; MONTENEGRO, M; BALASCH, M. Los limites de la metáfora lingüística: implicaciones de una perspectiva corporeizada para la práctica invastigadora e interventora. In: Política y Sociedad, v. 40, n. 1, p. 57-70, 2003. 